\title{
Wakaf Muhammadiyah dalam Membangun Pendidikan Berkemajuan di SMP Muhammadiyah Ahmad Dahlan Kota Metro
}

\author{
Dea Tara Ningtyas ${ }^{1}$, Nurul Mahmudah ${ }^{2}$, Supiah $^{3}$, Juldus R Paus ${ }^{4}$ \\ ${ }^{1,2}$ Fakultas Tarbiyah \\ ${ }^{3,4}$ Fakultas Syariah dan Ekonomi Islam \\ ${ }^{1,2}$ IAIN Metro Lampung, Indonesia \\ ${ }^{3}$ IAIN Sultan Amai Gorontalo, Indonesia \\ ${ }^{4}$ Universitas Negeri Manado, Indonesia \\ ${ }^{1}$ deataraningtyas@metrouniv.ac.id, ${ }^{2}$ nurulmahmudah@metrounic.ac.id, \\ ${ }^{3}$ supiahbd@gmail.com, ${ }^{4}$ udumdo@yahoo.co.id
}

\begin{abstract}
The writing of this research aims to explain the management and impact of waqf for education in SMP Muhammadiyah Ahmad Dahlan Metro City. As for the background in this writing is the demands and expectations of the community for the greater quality of education but the capacity of the government is not yet worth the demand of the community. So the waqf movement became one of the alternatives offered to answer the challenge. Waqf movement, especially in SMP Muhammadiyah Ahmad Dahlan aims to improve the quality of education in accordance with Muhammadiyah jargon namely "advanced education". This research is a qualitative study with this type of case study research. The data sources in this study consist of primary data sources and secondary data sources. Data collection techniques are conducted in the form of observations, interviews and documentation. The methods of data analysis are data reduction, data presentation and verification. The results of this study show that the waqf movement in SMP Muhammadiyah Ahmad Dahlan Metro City is supported not only by Muhammadiyah cadres but from sympathizers and the general public. The waqf development strategy carried out at SMP Muhammadiyah Ahmad Dahlan Kota Metro consists of (1) the conversion (substitution) of waqf assets, (2) promotion and socialization, (3) the management of waqf assets by prioritizing the allocation of waqf with regard to the 2015-2027 plan, (4) establishing partnerships and (5) strengthening the teachings of Al-Ma'un Muhammadiyah. The impact of waqf has a profound effect on the quality of education such as the improvement of school facilities and the education system in the school. Keywords: Waqf Muhammadiyah, Advanced Education
\end{abstract}

Penelitian ini bertujuan untuk memaparkan pengelolaan dan dampak wakaf bagi pendidikan di SMP Muhammadiyah Ahmad Dahlan Kota Metro. Adapun yang menjadi latar belakang dalam penulisan ini adalah tuntutan dan harapan masyarakat akan kualitas pendidikan yang lebih besar namun kapasitas yag dimiliki pemerintah belum sepadan dengan permintaan masyarakat. Sehingga gerakan wakaf menjadi salah satu alternative yang ditawarkan untuk menjawab tantangan tersebut. Gerakan wakaf khususnya di SMP Muhammadiyah Ahmad Dahlan bertujuan untuk meningkatkan mutu 
pendidikan sesuai dengan jargon Muhammadiyah yakni "pendidikan berkemajuan".Penelitian ini merupakan penelitian kualitatif dengan jenis penelitian studi kasus. Sumber data dalam penelitian ini terdiri dari sumber data primer dansumber data sekunder. Teknik pengumpulan data yang dilakukan berupa observasi, wawancara dan dokumentasi. Adapun metode analisis data yang dilakukan adalah reduksi data, penyajian data dan verifikasi. Hasil penelitian ini menunjukkan bahwa gerakan wakaf di SMP Muhammadiyah Ahmad Dahlan Kota Metro tidak hanya didukung oleh kader Muhammadiyah saja melainkan dari simpatisan dan masyarakat umum. Adapun strategi pengembangan wakaf yang dilakukan di SMP Muhammadiyah Ahmad Dahlan Kota Metro terdiri dari (1) penukaran (substitusi) harta wakaf, (2) promosi dan sosialisasi, (3) pengelolaan harta wakaf dengan memprioritaskan alokasi wakaf dengan memperhatikan renstra tahun 2015-2027, (4) menjalin kemitraan dan (5) Memperkuat ajaran Al-Ma'un Muhammadiyah. Dampak wakaf sangat berpengaruh terhadap mutu pendidikan seperti peningkatan fasilitas sekolah dan sistem pendidikan di sekolah tersebut.

Keywords: Muhammadiyah Waqf, Advanced Education.

\section{A. Pendahuluan}

Pendidikan merupakan isu sentral dalam konteks globalisasi untuk membangun sebuah peradaban. Hal ini juga diungkapkan oleh Sabar Budi Raharjo bahwasannya pemimpin di Negara maju mengungkapkan bahwasannya pendidikan merupakan hal yang sangat urgen dalam membangun sebuah negara. "As a nation, we now invest more in education than in defens". ${ }^{1}$ Oleh karenanya jika suatu negara kurang memedulikan isu pendidikan dengan serius, dapat diperkirakan bahwa negara tersebut dalam tahuntahun kedepan akan menjadi negara terbelakang. ${ }^{2}$

Sekolah sebagai sarana pendidikan formal sudah seharusnya mampu bersaing di era global dan mampu merespon kebutuhan masyarakat. Agar menjadi lembaga yang unggul dan berdaya saing tinggi serta diminati oleh masyarakat sekolah harus berbenah diri dengan berorientasi pada kebutuhan dan tuntutan global tanpa menghilangkan eksistensinya sebagai bangsa dan Negara yang berkarakter mulia. ${ }^{3}$ Oleh karenya pendidikan tidak boleh alergi terhadap nilai-nilai kemajuan zaman yang semakin dinamis. Sehingga lahirlah generasi-generasi tangguh yang terampil, beriman dan

\footnotetext{
${ }^{1}$ Sabar Budi Raharjo, "Evaluasi Trend Kualitas Pendidikan di Indonesia”, Jurnal Penelitian dan Evaluasi Pendidikan, No.2, 2012, h. 513

${ }^{2}$ Ibid.

${ }^{3}$ Prim Masrokan, Manajemen Mutu Sekolah, Strategi Peningkatan Mutu dan Daya Saing Lembaga Pendidikan islam (Yogyakarta: Ar-Ruz Media, 2013) h.8
} 
bertakwa pada Allah SWT. Cita-cita tersebut sudah diamanatkan dalam Sistem Pendidikan Nasional Nomor 20 tahun 2003 yaitu "Pendidikan Nasional bertujuan untuk mengembangkan potensi peserta didik agar menjadi manusia yang beriman dan bertaqwa kepada Tuhan Yang Maha Esa, berakhlak mulia, sehat, berilmu, cakap, kreatif, mandiri dan menjadi warga negara yang demokratis serta bertanggung jawab". ${ }^{4}$

Tanggung jawab pendidikan dalam melaksanakan amanat nasional bukan serta merta ada di pundak pemerintah saja, pihak swasta pun memiliki peran dalam mencapai cita-cita tersebut. Potensi pihak swasta untuk turut andil dalam bidang pendidikan diperkuat oleh maraknya fenomena wakaf. Penduduk Indonesia khususnya masyarakat muslim maupun organisasi-organisasi Islam sudah banyak melakukan wakaf dalam membangun akses pendidikan yang berkualitas dan berkemajuan salah satunya adalah organisasi Muhammadiyah.

Muhammadiyah Merupakan gerakan islam modernis yang tidak hanya terfokus pada kegiatan keagaaman saja melainkan kegiatan sosial, kesehatan dan pendidikan. Ketiga gerakan ini dipelopori Muhammadiyah sejak abad pertama. Dalam bidang pendidikan Muhammadiyah berkomitmen untuk mengusung pendidikan Islam berkemanjuan dengan merancang system pendidikan Islam modern untuk kemajuan umat dan masyarakat. Gerakan wakaf merupakan salah satu cara untuk mewujudkan cita-cita tersebut. Sikap Muhammadiyah yang bersemangat kedermawanan (filantropi) termanifestasi dalam amal usaha Muhammadiyah dibidang pendidikan dengan mendirikan sekolah-sekolah Islam modern dengan menerapkan pembelajaran yang bersifat holistik. Salah satu sekolah yang didirikan oleh Muhammadiyah dengan pembelajaran holistik adalah SMP Muhammadiyah Ahmad Dahlan Metro.

Sekolah Menengah Pertama (SMP) Muhammadiyah Ahmad Dahlan Metro berdiri pada tahun 2015. Sekolah ini dipelopori oleh kader kader Muhammadiyah dengan visi membawa perubahan. Sudah tercatat banyak prestasi yang ditorehkan oleh sekolah tersebut baik secara akademis maupun non akademis. Berikut capaian prestasi siswa tahun 2015-2019:

\footnotetext{
4 Departemen Pendidikan RI, Undang-Undang Nomor 20 Tahun 2003 Tentang Sistem Pendidikan Nasional (Jakarta: Sinar Grafika, 2004), h. 3
} 
Tabel 1. Prestasi Siswa SMP Muhammadiyah Ahmad Dahlan Metro

\begin{tabular}{|c|c|c|c|}
\hline Prestasi Kabupaten/Kota & Prestasi Provinsi & Prestasi Nasional & Prestasi Internasioal \\
\hline 1. $\mathrm{O} 2 \mathrm{SN}$ & 1. Gebyar Lintas & 1. Olympic & The Olympiade of \\
\hline 2. FLS2N & Fotrasi & Ahmad & Quranic Art \& \\
\hline 3. Walikota Cup & 2. Semarak PW & Dahlan V & Technology (OLYQ) \\
\hline 4. ASKOT & IPM & 2017 & 2017 \\
\hline 5. MAM Fesco & 3. LCT PAI & 2. FLS2N & \\
\hline 6. Forum Pelajar Islam & Tingkat Provinsi & 3. Kapolri Cup & \\
\hline$(\mathrm{FPI})$ & 4. Culture of Road & Taekwondo & \\
\hline 7. Muhi Exhibition & Safety & 4. OLSN & \\
\hline 8. MAM Fesco 2017 & 5. March Muhamd & & \\
\hline 9. Pekan Fisika & 6. FLS2N & & \\
\hline 10. HUT SMKN 3 Metro & 7. Robotik IBI & & \\
\hline 11. Pekan Olahraga & Darmjaya & & \\
\hline 12. Pelajar (POP) & 8. Dinas & & \\
\hline 13. Open Turnamen & Kebudayaan dan & & \\
\hline Stobright Education & Permusiuman & & \\
\hline 14. Jambore Daerah HW & 9. Taekwondo & & \\
\hline 15. Semarak pendidikan & Piala Gubernur & & \\
\hline 16. Paskatro Art & 10. $02 \mathrm{SN}$ & & \\
\hline 17. M3M Scout & 11. LCT Museum & & \\
\hline Competition & Lampung & & \\
\hline 18. Gala Siswa Indonesia & 12. Porprov VIII & & \\
\hline 19. MTQ Ke-14 Metro & 2017 & & \\
\hline 20. Amuse IX & 13. Unila Cup 3 & & \\
\hline
\end{tabular}

Sumber: TU SMP Muhammadiyah Ahmad Dahlan Metro

Berdasarkan data tersebut tercatat jumlah prestasi kabupaten/ kota sebanyak 20, jumlah prestasi provinsi sebanyak 13, jumlah prestasi nasional sebanyak 4 dan jumlah prestasi internasional sebanyak 1. Jadi, total keseluruhan prestasi siswa SMP Muhammadiyah Ahmad Dahlan Metro tahun 2015-2019 sebanyak 38.

Hemat penulis SMP Muhammadiyah Ahmad Dahlan hanya butuh waktu empat tahun untuk dapat melejitkan namanya dan mampu bersaing dengan sekolah-sekolah lainnya serta beradaptasi dengan perkembangan zaman. Prestasi-prestasi tersebut tidak terlepas dari upaya gerakan wakaf yang dilakukan oleh Muhammadiyah dalam menghimpun dana dari berbagai macam sumber baik dari kader Muhammadiyah, amal usaha Muhammadiyah, simpatisan maupun masyarakat umum. Kepercayaan tersebut tumbuh dikarenakan keseriusan Muhammadiyah dalam mendirikan sekolah-sekolah unggul yang mampu bersaing dengan perkembangan zaman. Sehingga sampai saat ini SMP Muhammadiyah Ahmad Dahlan Metro banyak diminati oleh masyarakat. Berikut data capaian siswa baru SMP Muhammadiyah Ahmad Dahlan Metro:

Tabel 2. Capaian Siswa Baru SMP Muhammadiyah Ahmad Dahlan 
Metro 2015-2019

\begin{tabular}{cccc}
\hline \multirow{2}{*}{ Tahun Pelajaran } & \multicolumn{2}{c}{ Jumlah } & \multirow{2}{*}{ Presentasi Siswa yang diterima } \\
\cline { 2 - 3 } & Pendaftar & Diterima & $67.3 \%$ \\
$2015 / 2016$ & 56 & 44 & $80.8 \%$ \\
$2016 / 2017$ & 163 & 132 & $84.9 \%$ \\
$2017-2018$ & 265 & 225 & $78.2 \%$ \\
$2018-2019$ & 358 & 280 & $45 \%$ \\
\hline
\end{tabular}

Sumber: TU SMP Muhammadiyah Ahmad Dahlan Metro

Berdasarkan data di atas animo masyarakat untuk mendaftar di SMPMu Ahmad Dahlan Metro terjadi peningkatan yang cukup baik dari tahun ketahun. SMPMu Ahmad Dahlan Metro semakin selektif dalam menerima siswa baru. Hal ini dibuktikan dengan jumlah presentase siswa yang diterima semakin sedikit. Dengan begitu SMPMu Ahmad Dahlan semakin memperhatikan input untuk menghasilkan output yang berkualitas.

Sangat banyak dampak positif dari gerakan wakaf dalam bidang pendidikan yang dilakukan Muhammadiyah. Hal ini tidak hanya dirasakan oleh warga Muhammadiyah saja melainkan juga masyarakat umum. Gerakan wakaf Muhammadiyah menjadi alternatif ketika kebutuhan dan tuntutan masyarakat akan kualitas pendidikan lebih besar daripada kapasitas yag dimiliki pemerintah. Sehingga hal ini penting untuk diteliti lebih jauh mengenai wakaf Muhammadiyah dalam membangun pendidikan berkemajuan. Penelitian ini menggunakan jenis penelitian kualitatif dengan jenis studi kasus. Pendekatan Kualitatif dengan jenis studi kasus ditunjukkan untuk mendapatkan informasi yang komprehensif terkait dengan filantropi Muhammadiyah. Penelitian kasus memperhatikan semua aspek yang penting dari suatu kasus-kasus yang diteliti. Penggunaan tipe penelitian ini akan dapat diungkapkan gambaran yang mendalam dan mendetail tentang suatu situasi atau objek. ${ }^{5}$ Hasil penelitian ini diharapkan dapat mengetahui bagaimana filantropi Muhammadiyah di SMP Muhammadiyah Ahmad Dahlan Metro dalam membangun pendidikan berkemajuan. Sumber data dalam penelitian ini terdiri dari sumber data primer dan sumber data sekunder. Teknik pengumpulan data dalam penelitian ini yakni observasi,

\footnotetext{
${ }^{5}$ Muri Yusuf, Metode Penelitian (Prenadamedia: Jakarta, 2014) h. 339.
} 
wawancara mendalam dan dokumentasi. Kemudian metode analisis data menggunakan reduksi data, display data dan verifikasi.

\section{B. Hasil Penelitian dan Pembahasan}

\section{Pengelolaan Wakaf}

Wakaf bukanlah wacana baru dalam dunia pendidikan. Wakaf sudah digagas sejak zaman nabi Muhammad SAW. Seiring berjalannya waktu wakaf terus mengalami dinamika dimana harta yang diwakafkan tidak hanya berupa benda tak bergerak tetapi juga dapat berupa uang tunai. Sejarah mencatat universitas al-azhar di Kairo, Universitas Zaituniyah di Tunis merupakan role model dalam wakaf pendidikan dimana mereka sangat mandiri dalam membiayai lembaga pendidikannya. Begitupun dengan pondok Gontor Darussalam di Ponorogo yang memiliki spirit yang sama terhadap kemandirian dalam mengelola lembaga pendidikan. Berangkat dari contoh-contoh lembaga pendidikan tersebut kini semakin banyak lembaga pendidikan yang dibangun oleh dana wakaf salah satunya lembaga pendidikan Muhammadiyah yakni SMP Muhammadiyah Ahmad Dahlan.

SMP Muhammadiyah Ahmad Dahlan merupakan sekolah yang digagas oleh Angkatan Muda Muhammadiyah (AMM) Metro yang tergabung dalam tim 12 (dua belas) orang sebagai ikhtiyar kolektif persyarikatan di dunia pendidikan. Berkesesuaian dengan misinya bahwa Muhammadiyah bertekad menyebarkan dakwah dan mencerdaskan bangsa dengan mendirikan sekolah-sekolah yang unggul dan Islami. Misi dalam membangun sekolah yang unggul dan islami merupakan manifestasi dari pemikiran K.H ahmad Dahlan yang menggagas tentang pendidikan berkemajuan. Pembangunan lembaga pendidikan yang berkemajuan tidak hanya didukung oleh lembaga itu sendiri tetapi juga masyarakat umum yang berkenan untuk mewakafkan harta nya di organisasi tersebut.

Data wakif berdasarkan catatan yang dihimpun terdiri dari dua jenis wakif yakni wakaf perseorangan dan wakaf lembaga. Wakaf perseorangan terdiri dari simpatisan dan donator tetap sedangkan wakaf lembaga terdiri amal usaha Muhammadiyah. Lembaga-lembaga tersebut diantaranya rumah sakit Muhammadiyah, Pimpinan Daerah 
Muhammadiyah (PDM), UM Metro, Muhammadiyah Bisnis Center, MCI Muhammadiyah, SMK N 3 Muhammadiyah, Pondok Pesantren At-Tanwir Metro.

Grafik 1. Wakif di SMP Muhammadiyah Metro

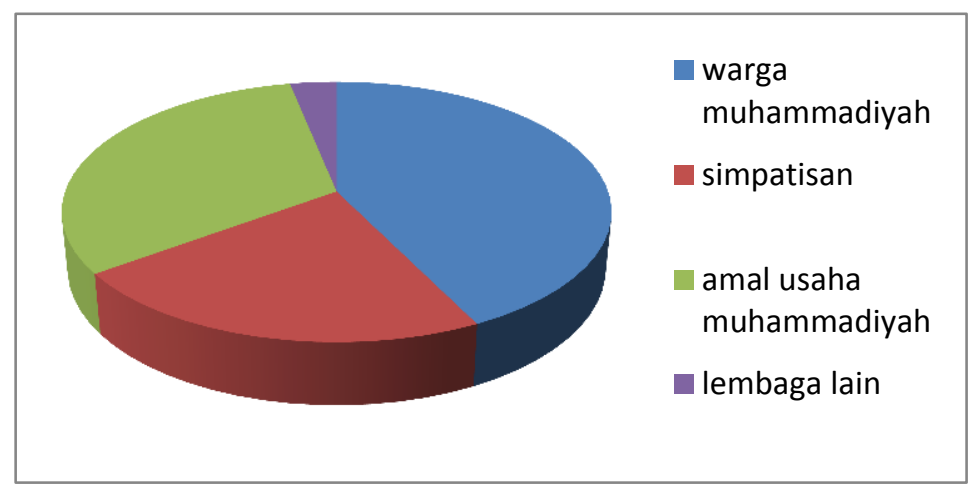

Gerakan wakaf dalam membangun pendidikan berkemajuan di SMP Muhammadiyah Ahmad Dahlan Metro menjangkau masyarakat umum dan simpatisan bukan hanya kader Muhammadiyah saja, salah satu yang mendasari wakif untuk menitipkan harta nya di sekolah tersebut adalah kepercayaan wakif terhadap lembaga tersebut, bahwa lembaga tersebut dapat menjawab kegelisahan dan kebutuhan masyarakat akan kualitas pendidikan.

Sejauh ini proses penggalangan dana wakaf digerakkan secara massif oleh humas dan seluruh warga smp Muhammadiyah Ahmad Dahlan. Selain mengandalkan relasi dilingkungan organisasi Muhammadiyah, pihak sekolah juga membangun relasi dengan masyarakat umum. Tim penggerak wakaf smp Muhammadiyah Ahmad Dahlan kerap menjemput bola dengan mempromosikan sekolah dan membagikan kartu wakaf bulanan bagi yang ingin menitipkan hartanya, (strategi ini meringankan wakif yang ingin berwakaf dengan system menabung karena wakaf dilakukan dengan mengurangi harta setiap bulan). peran pimpinan SMP Muhammadiyah Ahmad Dahlan juga sangat besar terhadap kepercayaan wakif dalam menitipkan harta nya disekolah tersebut. Hal ini dikarenakan para pendiri sekolah tersebut menjadi orang yang sangat ditokohkan khususnya oleh warga Muhammadiyah metro.

Pengelolaan wakaf yang dilakukan di SMP Muhammadiyah Ahmad Dahlan dilakukan oleh pimpinan beserta jajarannya di sekolah Muhammadiyah Ahmad Dahlan Metro. Strategi pengumpulan dana wakaf dilakukan dengan dua cara yaitu fundraising 
ke pihak luar dan fundraising ke pihak dalam yakni para pimpinan, guru dan pegawai sekolah diwajibkan membayar wakaf sesuai dengan nominal yang ditentukan. Pembayaran wakaf tersebut dilakukan dengan cara memotong gaji setiap bulan. Adapun teknik fundraising yang dilakukan adalah direct fundraising yaitu terknik secara langsung. Teknik fundraising ini bisa dilakukan komunikasi secara langsung kepada wakif melalui email, whatssap maupun presentasi langsung.

Berdasarkan hasil dari observasi dan wawancara Model pengembangan pengelolaan wakaf yang dilakukan untuk lembaga dalam membangun pendidikan yang berkemajuan. Maka model pengembangan wakaf yang dilakukan adalah:

1. Penukaran pengganti (substitusi) harta wakaf. Model substitusi berarti suatu pertukaran harta wakaf yang satu dengan yang lain, paling tidak memberikan pelayanan atau pendapatan yang sama tanpa perubahan peruntukan yang ditetapkan pemberi harta wakaf (wakif). Contohnya adalah pertukaran tanah wakaf milik SMP Muhammadiyah Ahmad Dahlan yang berada di wilayah jarang penduduk ditukar dengan tanah yang berada di wilayah yang strategis dan padat penduduk.

2. Promosi dan sosialisasi

Promosi dan sosialisasi adalah salah satu upaya untuk mengenalkan lembaga kepada masyarakat umum. Promosi dan sosialisasi di SMP Muhammadiyah dilakukan dengan 3 cara pendekatan:

a. Pendekatan keagamaan

wakaf sebagai ibadah sunnah diberikan porsi yang sama dengan zakat sebagai ibadah yang sangat urgen dari segi taqarub ila Allah. ${ }^{6}$ Wakaf juga merupakan sedekah jariyah yang pahalanya dijanjikan Allah akan terus mengalir walapun wakif telah meninggal dunia. Oleh karenanya pendekatan keagamaan seperti ini kerap sekali dilakukan oleh lembaga dalam kajian-kajian keagamaan di organisasi Muhammadiyah maupun dilakukan dengan silaturahin perseorangan.

b. Pendekatan kesejahteraan sosial secara social wakaf memiliki peran yang sangat strategis dalam mengentaskan kemiskinan dan kebodohan. Wakaf memiliki kontribusi yang cukup solutif dalam

\footnotetext{
${ }^{6}$ Rozalinda. Manajemen wakaf..., h. 372
} 
menjawab persoalan tersebut. Pemahaman secara social terus dilakukan oleh lembaga secara terus menerus dengan pola pendekatan penyadaran akan situasi social yang terjadi saat ini. Sehingga calon wakif akan tergerak hatinya untuk berpartisipasi menyumbangkan hartanya atau berwakaf untuk kepentingan umum.

c. Pendekatan bukti pengelolaan wakaf

Pendekatan bukti pengelolaan wakaf dilakukan dalam rangka menjaga kepercayaan wakif terhadap lembaga. Adapun cara yang dilakukan lembaga untuk menjaga kepercayaan wakif adalah mengundang waqif ke lembaga, memberikan progress report secara transparan dan menjalin silaturahim dengan baik melalui tatap muka maupun media elektronik.

3. Mengelola harta wakaf dengan memprioritaskan alokasi wakaf dengan memperhatikan renstra tahun 2015-2027. Tahap 1 2015-2019 penyiapan infrastruktur I, tahap 2 2019-2023 pemenuhan infrastruktur tahap II dan tahap III terwujudnya sekolah unggul dan modern. ${ }^{7}$

a. Tahap pertama (2015 - 2019)

Kebijakan program pada tahap pertama/awal rintisan berdirinya SMPMu Ahmad Dahlan ini difokuskan kepada:

1) Penyiapan dan pematangan konsep/blueprint sekolah, Rencana Strategis, Visi, Visi, Tujuan serta arah kebijakan yang jelas

2) Penyiapan infrastuktur dasar tahap I, seperti pembangunan ruang kelas, kantor, Laboratorium, WC, sarana ibadah, dan penunjang lainnya

3) Pembentukan karakter building, dan pembentukan brand image, kepada masyarakat. Hal ini dilakukan dengan cara penguatan pemahaman terhadap Visi dan Misi sekolah kepada seluruh warga sekolah serta sosialisasi kepada masyaraka melalui berbagai media, yang disertai kerja keras dan kesungguhan dalam mengelola institusi, sehingga dapat menujukan prestasi yang terbaik kepada masyarakat dalam rangka membangun eksistensi dan kepercayaan masyarakat.

\footnotetext{
${ }^{7}$ Tim Penyusun, Profil Pablik SMP Muhammadiyah Ahmad Dahlan, Tahun 2017, h. 15-17
} 
b. Tahap kedua (2019 - 2023)

Pada tahap kedua program jangka panjang, SMPMu Ahmad Dahlan menitikberatkan pada :

1) Penataan dan penguatan sitem oraganisasi kelembagaan, penguatan jaringan, menuju sekolah yang unggul, maju dan akuntabel.

2) Pemenuhan infrasturktur tahap II, pada tahap ini diharapkan semua kebutuhan sarana dan prasarana pembelajaran secara bertahap sudah dapat terpenuhi

3) Penguatan dan pengembangan Sumber Daya Manusia, bagi terciptanya kondisi yang ideal bagi terwujudnya Visi sebagai sekolah unggul

c. Tahap ketiga $(2023-2027)$

Tahap ketiga program jangka panjang, SMPMu Ahmad Dahlan memfokuskan pada :

1) Transformasi (perubahan cepat kearah kemajuan), sekolah dengan sistem organisasi yang profesional, unggul, maju dan modern,

2) Terciptanya faktor - faktor pendukung dan Kondisi yang ideal bagi terwujudnya Visi dan Misi SMPMu Muhammadiyah Dahlan Mejadi pilihan pertama

4. Menjalin kemitraan

Lembaga dalam hal ini giat menjalin kemitraan dengan institusi lain. Salah satu yang dilakukan oleh SMP Muhammadiyah Ahmad Dahlan adalah menjalin mitra dengan kemetrian tenaga kerja. Salah satu hasil dari kerjasama tersebut adalah diberikannya dana pembangunan unit bahasa di SMP Muhammadiyah Ahmad Dahlan kota metro.

5. Memperkuat ajaran Alma'un Muhammadiyah

Eksistensi wakaf di lembaga pendidikan Muhammadiyah berakar dari ajaran alma'un yang secara tidak langsung memberikan dorongan kepada Muhammadiyah untuk menyerukan kebaikan dalam mengakomodir sikap derma. Salah satu yang dilakukan organisasi Muhammadiyah dalam menghidupkan pendidikannya adalah memanfaatkan wakaf yang ada atau dikenal dengan istilah Amal Usaha Muhammadiyah (AUM). Amal usaha 
Muhammadiyah sebagai bentuk pemanfaatan dari wakaf, memiliki karakteristik yang unik yakni didasarkan pada spirit Qur'an surat Al- Ma'un.

\section{Dampak Wakaf}

Wakaf memiliki dampak yang sangat besar terhadap kemajuan lembaga pendidikan. Indikator dalam mengukur perkembangan sekolah tersebut dapat dilihat kelayakan fasilitas, sistem pendidikan maupun outputnya. Selain itu peforma pendidikan atas penyediaan dan keterjangkauan layanan pendidikan serta mutu layanan pendidikan sangat mempengaruhi pembangunan pendidikan berkemajuan di SMP Ahmad Dahlan Kota Metro menjadi sekolah yang banyak diminati dan dapat bersaing dilingkup wilayah, nasional maupun internasional.

\section{Dampak wakaf terhadap fasilitas sekolah}

Wakaf dalam peningkatan jumlah fasilitas sangat berpengaruh terhadap mutu pendidikan. Pencapaian mutu pendidikan sejalan dengan tujuan pendidikan nasional:

"Mengembangkan kemampuan dan membentuk watak serta peradaban bangsa yang bermartabat dalam rangka mencerdaskan kehidupan bangsa, bertujuan untuk berkembangnya potensi peserta didik agar menjadi manusia yang beriman dan bertakwa kepada Tuhan Yang Maha Esa, berakhlak mulia, sehat, berilmu, cakap, kreatif, mandiri dan menjadi warga negara yang demokratis serta bertanggung jawab. ${ }^{8}$

Secara ringkas dapat dijabarkan bahwa pelaksanaan pembelajaran dalam pendidikan nasional berpusat pada peserta didik agar dapat: (a) belajar untuk beriman dan bertakwa kepada Tuhan Yang Maha Esa, (b) belajar untuk memahami dan menghayati, (c) belajar untuk mampu melaksanakan dan berbuat secara efektif, (d) belajar untuk hidup bersama dan berguna bagi orang lain, dan (e) belajar untuk membangun dan menemukan jati diri melalui proses belajar yang aktif, kreatif, efektif dan menyenangkan. ${ }^{9}$ Kemudian untuk menjamin terwujudnya hal tersebut diperlukan adanya sarana dan prasarana yang memadai. Sarana dan prasarana yang memadai tersebut harus memenuhi ketentuan minimum yang ditetapkan dalam standard sarana dan prasarana.

\footnotetext{
8 Departemen Pendidikan RI, Undang-Undang Nomor 20 Tahun 2003 Tentang Sistem Pendidikan Nasional..., hlm. 3

${ }^{9}$ Lampiran Peraturan Menteri Pendidikan Nasional Nomor 24 Tahun 2007 Tanggal 28 Juni 2007
} 
Menurut data yang tercatat, sarana dan prasarana di SMP Muhammadiyah Ahmad Dahlan Kota Metro tergolong baik dan layak. Demikian juga dengan jumlah ruangan kelas yang sebanding dengan jumlah total rombongan belajar berdasarkan jumlah rasio siswa di SMP Muhammadiyah Ahmad Dahlan. Jumlah rombongan belajar di SMP Muhammadiyah Ahmad Dahlan terdiri dari 25 rombel, dengan rincian kelas 7 terdiri dari sepuluh rombel, kelas 8 terdiri dari delapan rombel dan kelas 9 terdiri dari 7 rombel. Sedangkan jumlah siswa dalam satu rombongan belajar maksimal terdiri dari 32 siswa. kondisi ini sesuai dengan apa yang dituangkan dalam Permendikbud Nomor 17 Tahun 2017, adapun ketentuannya sebagai berikut.

Tabel 3. Jumlah Rombel Per Satuan pendidikan

\begin{tabular}{lccc}
\hline No & $\begin{array}{c}\text { Satuan } \\
\text { Pendidikan }\end{array}$ & $\begin{array}{c}\text { Jumlah Rombongan } \\
\text { Belajar }\end{array}$ & $\begin{array}{c}\text { Jumlah Maksimum Peserta didik per } \\
\text { Rombongan Belajar }\end{array}$ \\
\hline 1 & SD/MI & $6-24$ & 28 \\
2 & SMP/MTs & $3-33$ & 32 \\
3 & SMA/MAN & $3-36$ & 36 \\
4 & SMK & $3-72$ & 36 \\
5 & SDLB & 6 & 5 \\
6 & SMPLB & 3 & 8 \\
7 & SMALB & 3 & 8 \\
\hline
\end{tabular}

Tabel jumlah rombongan belajar per satuan pendidikan dan jumlah maksimum peserta didik dalam setiap rombongan belajar.

Demikian dengan jumlah fasilitas lainnya seperti ruang belajar penunjang (perpustakaan, lab. Ipa, lab computer), ruang kantor (ruang kepala sekolah, ruang guru, ruang tata usaha dan kantor TU boarding) dan ruang penunjang (gudang, KM/WC guru, wc siswa, BK, UKS, Osis/IPM, Boarding School Putra, Boarding School Putri, dan lobi) tergolong baik dan telah memenuhi standar Peraturan Menteri Pendidikan Nasional Nomor 24 Tahun 2007 tentang Standard Sarana Dan Prasarana Sekolah/Madrasah Pendidikan Umum. Sebagaimana dijelaskan bahwa standard sarana dan prasarana ini mencakup:

a. kriteria minimum sarana yang terdiri dari perabot, peralatan pendidikan, media pendidikan, buku dan sumber belajar lainnya, teknologi informasi dan komunikasi, serta perlengkapan lain yang wajib dimiliki oleh setiap sekolah/madrasah, 
b. kriteria minimum prasarana yang terdiri dari lahan, bangunan, ruang-ruang dan instalasi daya dan jasa yang wajib dimiliki oleh setiap sekolah/madrasah. ${ }^{10}$

2. Dampak Wakaf terhadap Sistem Pendidikan di SMP Muhammadiyah Ahmad Dahlan

Wakaf bagi steakholder SMP Muhammadiyah Ahmad Dahlan sangat besar dampaknya dalam membangun pendidikan berkemajuan di sekolah tersebut. Wakaf menjadi alat untuk mencapai cita-cita pendiri dalam membangun pendidikan Muhammadiyah yang berkemajuan. Mengutip pernyataan Mohammad Ali tentang pendidikan berkemajuan atau progresif-religius bahwasannya pendidikan harus berorientasi pada akhirat dan mencita-citakan kemajuan hidup umat Islam. Ketercapaian tiga hal tersebut tidak terlepas dari peran akal, pertumbuhan individu secara utuh dan keterlibatan dalam kehidupan sosial. Konsep pendidikan berkemajuan yang ditawarkan KH Ahmad Dahlan diimplementasikan oleh SMP Muhammadiyah Ahmad Dahlan dengan menerapkan sistem pendidikan berbasis holistic.

Pendidikan holistik merupakan filsafat pendidikan yang melahirkan suatu metode pendidikan dengan cara mengembangkan semua potensi manusia untuk menemukan tujuan hidupnya melalui potensi social-emosional, potensi intelektual, moral kreatifitas dan spiritual dalam rangka membangun manusia seutuhnya. ${ }^{11}$

Ada beberapa dasar pemikiran yang melatar belakangi inisiatif pendirian SMPMU Ahmad Dahlan sebagai sekolah yang menerapkan pendidikan berbasis holistik. Pertama, Tingginya harapan para orang tua masa kini yang menginginkan konsep pendidikan holistik yaitu sebuah lembaga pendidikan yang mengintegrasikan potensi-potensi kecerdasan peserta didik baik kecerdasan ruhiyah, kecerdasan intelektual, kecerdasan emosional sekaligus kecerdasan sosialnya dalam bingkai dan sendi-sendi nilai-nilai Islam, keunggulan dan keluhuran moral/akhlak serta keunggulan dalam menguasai ilmu pengetahuan dan

\footnotetext{
10 Ibid.

${ }^{11}$ Herry Widyastono, "Muatan Pendidikan Holistik Dalam Kurikulum Pendidikan Dasar Dan Menengah", Jurnal Pendidikan dan kebudayaan, Vol. 18, No. 4 Tahun 2012, h. 3
} 
teknologi. ${ }^{12}$ Harapan terbesar para orang tua terhadap putra-putrinya adalah agar menjadi generasi yang sholeh dan sholehah, berakhlakul karimah, menguasai ilmu pengetahuan yang luas dan memberikan manfaat bagi masyarakat. Kedua, semakin berkembangnya ilmu pengetahuan, teknologi dan informasi saat ini telah mencoba menggeser dan mengobrak-abrik tata nilai agama dan sosial yang ada di dalam masyarakat. Disadari atau tidak bahwa dampak negatif dari kemajuan teknologi dan informasi akan deras menerjang tata nilai dan hidup yang ada sekarang dan kondisi ini tidak bisa dihindari. Hal inilah yang menyebabkan kekhawatiran dan kegelisahan para orang tua atas kehidupan generasi putra-putri di masa yang akan datang. Maka, mau tidak mau, kesadaran sejak dini para orang tua untuk mendidik dan menyekolahkan putra-putrinya di lembaga pendidikan yang membekali, menanamkan pemahaman dan pengamalan nilai-nilai keagamaan, sekaligus memperkuat kecakapan dan penguasaan ilmu pengetahuan dan teknologi kepada peserta didik agar mampu menjawab tantangan zaman adalah sebuah keharusan dan menjadi kebutuhan mendesak para orang tua. ${ }^{13}$

Pendidikan holistik di SMP Muhammadiyah Ahmad Dahlan tertuang dalam nilai-nilai karakter sebagai berikut:

a. Memiliki kemantapan aqidah, kebenaran dalam beribadah, dan berakhlaq mulia;

b. Tertib beribadah, belajar dan berorganisasi;

c. Mampu membaca, menulis dan menghafal ayat-ayat Al-Qur`an dengan baik dan benar;

d. Berpenampilan secara wajar dan rapi;

e. Berdisiplin tinggi, jujur dan percaya tinggi;

f. Mencintai ilmu pengetahuan dan menguasai teknologi informasi;

g. Memiliki keberanian dan keterbukaan yang didasari akhlak mulia;

h. Mampu berkomunikasi dengan bahasa Indonesia yang baik dan benar serta bahasa asing (Arab/Inggris/Jepang);

i. Mampu berkompetisi dengan siswa sekolah/lembaga lain dan berprestasi;

\footnotetext{
${ }^{12}$ Tim Penyusun, Profil Pablik SMP Muhammadiyah Ahmad Dahlan ..., h. 9-10

13 Ibid.
} 
j. Memiliki prestasi dalam bidang akademik dan non akademik yang baik. ${ }^{14}$

Nilai-nilai tersebut diharapkan mampu mencetak lulusan SMPMu Ahmad Dahlan dititikberatkan pada 5 (lima) kualitas:

a. Kualitas ke-Islaman dan ke-Muhammadiyahan

Kekuatan aqidah, tertib dan benar dalam beribadah, berakhlak mulia, fasih membaca Al-Qur`an, dan memiliki hafalan Al-Qur`an minimal 3 jus (jus 28, 29 dan 30);

b. Kualitas Keilmuan

Penguasaan ilmu pengetahuan dan teknologi, meningkatnya nilai akademik, banyaknya lulusan yang melanjutkan studi di sekolah-sekolah unggul dan berkualitas;

c. Kualitas Kebahasaan

Memiliki keterampilan dasar/kecakapan berbahasa Indonesia yang baik dan benar serta bahasa asing (Arab/Inggris/Jepang);

d. Kualitas Kemasyarakatan

Menjadi tauladan dan memberi manfaat yang besar bagi masyarakat;

e. Kualitas Keindonesiaan

Memiliki sikap kebangsaan dan nasionalisme yang tinggi. ${ }^{15}$

Implementasi pendidikan berbasis holistik di SMP Muhammadiyah Ahmad Dahlan Metro tetap memperhatikan substansi pembelajaran yang di tempuh dalam satu jenjang pendidikan selama 3 tahun, mulai kelas VII sampai dengan kelas IX. Struktur kurikulum disusun berdasarkan standar kompetensi lulusan dan standar kompetensi mata pelajaran. Secara makro, prosentase struktur kurikulum SMP Muhammadiyah Ahmad Dahlan sebagaimana tergambar dalam grafik berikut ini :

\footnotetext{
${ }^{14}$ Ibid., h. 13

${ }^{15}$ Ibid., h. 14
} 
Grafik 2 : Struktur Kurikulum SMP Muhammadiyah Ahmad Dahlan Metro

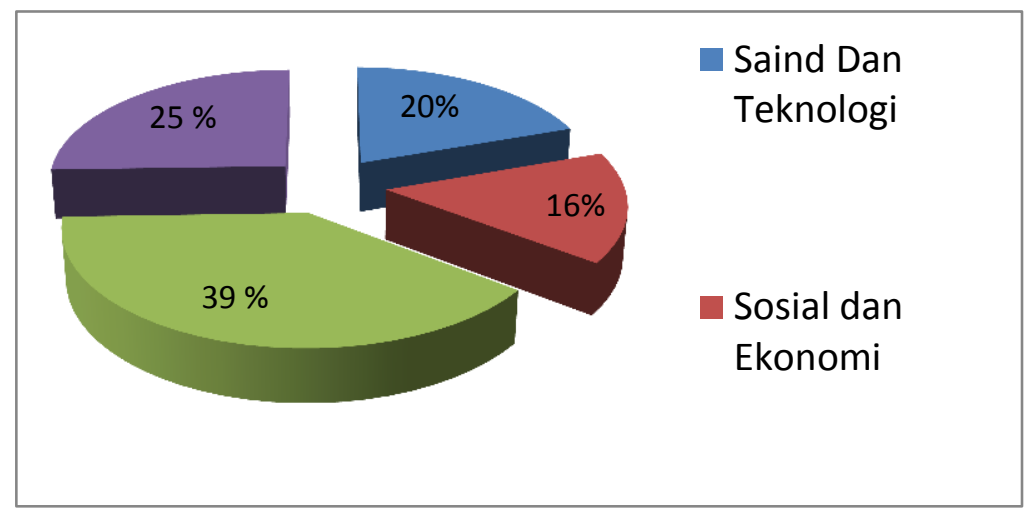

Adapun stategi pelaksanaan pendidikan berbasis holistik meliputi 7 aspek yakni:

a. Proses pendidikan dan pembelajaran terintegrasi dengan nilai-nilai Islam (konsep pendidikan holistik berbasis Islam) bersumber pada Al Quran dan Hadits. Pendidikan holistik berbasis nilai-nilai Islam diarahkan pada pembentukan peserta didik yang unggul dalam moral, intelektual dan sosial;

b. Proses pendidikan pendidikan dan pembelajaran dilaksanakan dalam bentuk full day school. Pembelajaran full day school (pembelajaran sehari penuh kecuali jum'at dan sabtu) dilaksanakan selama 6 (enam) hari efektif (Senin - Sabtu).

c. Proses pendidikan dan pembelajaran untuk tahap selanjutnya akan menerapkan konsep boarding school. Strategi ini dalam rangka memberikan penguatan kepada para peserta didik dalam melakukan pendalaman, pemahaman dan pengamalan nilai-nilai Islam dalam kehidupan sehari-hari serta sebagai upaya pembentukan karakter bagi peserta didik yang berakhlak mulia, unggul dan berprestasi;

d. Menjadikan peserta didik sebagai subjek pendidikan dan pembelajaran. Dalam praksisnya bagaimana menjadikan peserta didik sebagai individu yang aktif belajar, menggali seluas mungkin ilmu pengetahuan, dan guru menjadi pendamping, pembimbing dan fasilitator pendidikan dan pembelajaran dalam menfasilitasi pengembangan potensi, bakat dan kemampuan peserta didik;

e. Proses pendidikan pendidikan dan pembelajaran dilaksanakan secara kontekstual. Belajar pada realitas lingkungan/dunia nyata dan menjadikan alam dan situasi social sebagai media pembelajaran. Tidak hanya sekedar belajar tekstual dan verbalisme (ceramah dan berlatih di kelas secara khayal), 
f. Menjadikan masjid sebagai pusat pembelajaran dan pengembangan keilmuan warga sekolah. Masjid secara fisik dan mental dijadikan sebagai tempat bagi pengembangan berbagai aktifitas kajian, pembelajaran, dan pelatihan yang berbasis nilai-nilai Islam;

g. Proses pendidikan dan pembelajaran didukung dengan basis teknologi informasi. Kualitas sarana dan prasarana pendidikan dan pembelajaran berbasis teknologi informasi adalah untuk menjawab tantangan dan kebutuhan efektifitas dan efesiensi proses kegiatan belajar mengajar yang lebih berkemajuan;

h. Selama proses pendidikan dan pembelajaran, siswa didampingi oleh Guru BK/Konselor professional. Proses ini dilakukan dalam rangka pengembangan diri, mencapai tugas-tugas perkembangan secara optimal, membentuk kepribadian (personality) yang mandiri serta mendampingi/membantu siswa dalam memecahkan masalah pribadi, sosial, belajar dan karirnya. ${ }^{16}$

Strategi-strategi tersebut diharapkan mampu menciptakan generasi-genarsi unggul Seperti yang dikatakan oleh Ahmad Dahlan tentang pendidikan Muhammadiyah berkemajuan bahwa manusia khalifah di bumi ini harus mampu mengemban tugasnya dan berpikir solutif, sebab manusia diberikan akal untuk menjawab problematika yang ada baik masalah-masalah personal, sosial, kebangsaan maupun global. Tentunya pendidikan sangat berperan penting dalam mengasah dan mengembangkan potensi tersebut agar tumbuh optimal. Optimalisasi akal dan potensi tersebut dapat diukur dengan kemampuan dan kesanggupannya dalam memecahkan problematika kehidupan.

\section{Kesimpulan}

Gerakan wakaf di SMP Muhammadiyah Ahmad Dahlan tidak hanya menjangkau kader Muhammadiyah saja tetapi juga masyarakat umum. Model pengembangan pengelolaan wakaf yang dilakukan SMP Muhammadiyah Ahmad Dahlan meliputi enukaran pengganti (substitusi) harta wakaf, promosi dan sosialisasi, mengelola harta wakaf dengan memprioritaskan alokasi wakaf dengan memperhatikan

\footnotetext{
${ }^{16}$ Ibid., h. 19-20
} 
| Dea Tara Ningtyas, DKK | Wakaf Muhammadiyah dalam Membangun Pendidikan...

renstra tahun 2015-2027, menjalin kemitraan, memperkuat ajaran Alma'un Muhammadiyah.

Adapun dampak wakaf di SMP Muhammadiyah Ahmad Dahlan berpengaruh besar terhadap mutu lembaga SMP Muhammadiyah Ahmad Dahlan Kota Metro Indikator tersebut dapat dilihat dalam percepatan peningkatan fasilitas sekolah maupun system pendidikan di sekolah tersebut. Dampak wakaf terhadap peningkatan fasilitas sekolah telah sesuai dengan acuan Peraturan Menteri Pendidikan Nasional Nomor 24 Tahun 2007 Tanggal 28 Juni 2007 tentang standard sarana dan prasarana. Begitupun dengan system pendidkan di SMP Muhammadiyah Ahmad Dahlan yang sudah mengacu pada pendidikan berbasis holistik. Pendidikan holistik sangat relevan dengan tujuan pendidikan nasional yang tertuang dalam Undang-Undang Nomor 20 Tahun 2003 Tentang Sistem Pendidikan Nasional bahwa pendidikan bertujuan untuk membentuk manusia seutuhnya.

Pengelolaan wakaf tunai sebaiknya dikelola dengan mengacu pada wakaf produktif, dimana wakaf tersebut diarahkan pada sektor produktif dengan menjalin kerjasama dengan lembaga yang telah memiliki reputasi yang baik. Sehingga wakaf tunai yang telah dikumpulkan dapat terus berkembang. Lembaga juga sebaiknya meningkatkan kapasitas pengelola wakaf agar dapat maksimal menjalankan tugasnya. 


\section{DAFTAR PUSTAKA}

Aan Nasrullah, "Pengelolaan Dana Filantropi Untuk Pemberdayaan Pendidikan Anak Dhuafa”, Jurnal Pendidikan Sekolah Tinggi Agama Islam STAI Miftahul 'Ula, Vol. 12 No. 1, Juni: 2015.

Akmaludin. 2017. "Peran Wakaf dalam Amal Usaha Pendidikan Pimpinan Cabang Muhammadiyah (PCM) Bengkulu IV Kota Bengkulu", Tesis. Program Pasca Sarjana IAIN Bengkulu.

Amelia Fauzia. 2013. Filantropi Islam. Gading Publishing: Yogyakarta.

Basrowi. 2008. Memahami Penelitian Kualitatif . Jakarta: Rineka Cipta

Departemen Pendidikan RI. 2004. Undang-Undang Nomor 20 Tahun 2003 Tentang Sistem Pendidikan Nasional. Jakarta: Sinar Grafika

Hafidz Arfandi, "Studi Kasus atas Motif dan Strategi Gerakan Filantropisme Muhammadiyah dalam Menopang Keterbatasan Negara", Artikel, sumber academia.edu.dokumen.

Hamid Patilima. 2013. Metode Penelitian Kualitatif, cet. Ke-4. Bandung: Alfabeta

Herry Widyastono, "Muatan Pendidikan Holistik Dalam Kurikulum Pendidikan Dasar Dan Menengah", Jurnal Pendidikan dan kebudayaan, Vol. 18, No. 4 Tahun 2012.

Kathryn M. Bartol dan David C. Martin. 1998. Management. New York: Mc.Graw Hill

Lampiran Peraturan Menteri Pendidikan Nasional Nomor 24 Tahun 2007 Tanggal 28 Juni 2007

Lexy J. Moleong. 2005. Metode Penelitian Kualitatif. bandung: Remaja Rosda Karya.

--------. 2010. Metodologi Penelitian Kualitatif. Bandung: Remaja Rosdakarya.

Mardani. 2011. Ayat-Ayat dan Hadis Ekonomi Syariah, Jakarta: Rajawali Pers

Masri Singaribuan dan Sofyan Effendi. 1989. Metode Penelitian Survey. Jakarta: LP3ES

Miles dan Huberman. 2002. Analisis Data Kualitatif . Jakarta: UI Press

Muri Yusuf. 2014. Metode Penelitian Prenadamedia: Jakarta

Muri Yusuf. Metode Penelitian. Prenamedia: Jakarta

Prim Masrokan. 2013. Manajemen Mutu Sekolah, Strategi Peningkatan Mutu dan Daya Saing Lembaga Pendidikan Islam. Yogyakarta: Ar-Ruz Media

Rozalinda. 2016. Manajemen Wakaf Produktif . Jakarta: PT Raja Grafindo Persada Siah Khosyi'ah. 2010. Wakaf dan Hibah. Bandung: CV Pustaka Setia

Suharsimi Arikunto. Prosedur Penelitian Suatu Pendekatan Praktik. Jakarta: Rineka Cipta

Tim Penyusun. 2017. Profil Pablik SMP Muhammadiyah Ahmad Dahlan. Metro: SMP Muhammadiyah Ahmad Dahlan

Nurul Ima. 2012. "Wakaf dan Kemandirian Pendidikan (Studi Pengelolaan Wakaf di Pondok Modern Darussalam Gontor Ponorogo)", Disertasi. Program Pascasarjana IAIN Walinsongo Semarang: Semarang

Mohamad Ali, “Menuju Teorisasi Pendidikan Berkemajuan”, Jurnal Tajdida, Vol. 15, No. 2, Desember 2017.

Mohamad Ali, dkk, "pendidikan Berkemajuan: Refleksi Praksis Pemikian K.H Ahmad Dahlan", Jurnal Pembangunan Pendidikan: Fondasi dan Aplikasi, Vol.4, No. 1, Juni 2016 
| Dea Tara Ningtyas, DKK | Wakaf Muhammadiyah dalam Membangun Pendidikan...

Puspita Rachman dan Sri Herianingrum, "Pemberdayaan Wakaf Tunai Pada Baitul Maal Hidayatullah Di Surabaya Dalam Bidang Pendidikan", Jurnal Ekonomi Syariah Teori dan Terapan Vol. 3 No. 8 Tahun 2016

Republika, manajemen fundraising dalam penghimpunan harta wakaf, 16 desember 2008

Sabar Budi Raharjo, "Evaluasi Trend Kualitas Pendidikan di Indonesia", Jurnal Penelitian dan Evaluasi Pendidikan, No.2, 2012

Wahyu Handoko, "Filantropi Pendidikan untuk menumbuhkan mutu madrasah di MI Muhammadiyah Kaweron Muntilan Magelang”, Skripsi, 2018. 